\title{
Changes in intraocular pressure and horizontal pupil diameter during use of topical mydriatics in the canine eye
}

\author{
Liga Kovalcuka ${ }^{1, *}$, Agris Ilgazs ${ }^{1}$, Dace Bandere ${ }^{2}$ and David L. Williams ${ }^{3}$ \\ ${ }^{1}$ Latvia University of Agriculture, Faculty of Veterinary Medicine, Clinical Institute, K. Helmaña iela 8, Jelgava, \\ LV-3004, Latvia \\ ${ }^{2}$ Riga Stradinš University, Faculty of Pharmacy, Department of Pharmaceutical Chemistry, Dzirciema iela 16, Rìga, \\ LV-1007, Latvia \\ ${ }^{3}$ University of Cambridge, Department of Veterinary medicine, United Kingdom
}

\begin{abstract}
The objective of this study was to determine the effects of topical $0.5 \%$ tropicamide, $1 \%$ atropine sulphate and $10 \%$ phenylephrine hydrochloride ophthalmic solutions on intraocular pressure (IOP) and horizontal pupil diameter (HPD) in the dog during the first hour after treatment. Forty clinically and ophthalmologically normal canine patients (between the ages of 2 and 6 years) of varying breed and sex were used in this study. Animals were randomly divided into four groups of ten and given one drop of tropicamide, atropine, phenylephrine or saline into one eye. IOP and HPD were measured in both eyes every 5 minutes for 60 minutes. Tropicamide increased IOP by $8.8 \pm 4.0 \mathrm{mmHg} 35$ minutes post-treatment compared to pre-treatment $(\mathrm{P}<0.01)$ only in treated eye. IOP in the contralateral eye did not increase. With atropine the maximum increase in IOP was $2.6 \pm 2.8 \mathrm{mmHg}$ at 20 minutes post treatment in the treated eye $(\mathrm{P}<0.01)$. IOP in the contralateral eye did not increase. Phenylephrine increased IOP by $2.3 \pm 2.1 \mathrm{mmHg}(\mathrm{P}<0.05)$ 10 minutes after treatment. Also in the untreated eye IOP increased by $2.3 \pm 2.1 \mathrm{mmHg}, 20$ minutes post-treatment. Maximum HPD in eyes treated with tropicamide occurred at 55 minutes and with atropine at 60 minutes. There were no HPD changes in the contralateral, untreated eye. Topical 10\% phenylephrine showed maximal pupil dilation 60 minutes after treatment, but the HPD of the - untreated eye slightly decreased at 15 minutes, but this change only reached statistical significance at 40 min post- treatment $(\mathrm{P}<0.05)$. Normal saline showed no influence on IOP or HPD. The drugs investigated here show a significant increase in IOP after mydriatics.
\end{abstract}

Keywords: Atropine sulphate, Horizontal pupil diameter, Intraocular pressure, Phenylephrine, Tropicamide.

\section{Introduction}

In ophthalmology mydriatics - specifically tropicamide hydrochloride and atropine sulphate - are employed to provide pupil dilation: during examination of the posterior segment of the eye (tropicamide) and as therapeutic agents for treatment of uveitis (atropine) by relieving ciliary spasm through cycloplegia and preventing formation of synechiae through mydriasis. The phenylephrine is used to localize the site of sympathetic denervation in Horner's syndrome, producing mydriasis as part of sympathomimetic action (Smith and Raynard 1992; Ward, 1998).

In humans an increase of intraocular pressure (IOP) has been observed after use of topical mydriatics such as atropine (Gartner and Billet, 1957), tropicamide and phenylephrine (Harris 1968; Harris and Galin, 1969; Rengstorff and Doughty, 1982) both in normal subjects and in patients with narrow filtration angle glaucoma (Harris and Galin, 1969) and with primary open angle glaucoma (Shaw and Lewis, 1986; Marchini et al., 2003). Latest report in five years old girl presented to the hospital for a routine retina check-u, after pupil dilation with $1 \%$ tropicamide and $10 \%$ phenylephrine for retinal examination, showed an acute elevation of intraocular pressure (Wu et al., 2015).

Effects of topical $1 \%$ atropine, $0.5 \%$ tropicamide, $1 \%$ homatropine, $10 \%$ phenylephrine, and $2 \%$ ibopamine on IOP and pupil diameter has been investigated in sheep. Topical atropine, tropicamide, and homatropine induced pupil dilation but did not change IOP in eyes of healthy sheep, but phenylephrine did not change any of the parameters evaluated (Ribeiro et al., 2014). Hacker and Farver (1988) investigated whether use of mydriatics could cause an increase in intraocular pressure in dogs and reported negative findings. However, these researchers measured the IOP before drug administration and at maximal pupil dilation but never during the process of pupil dilation, but Grozdanic et al. (2010) showed increase of IOP in dogs with closed angle glaucoma.

The parasympatholytic agent tropicamide is a cholinergic antagonist used in animals for pupil dilation because of its rapid action and short duration (Marchini et al., 2003). In several studies with dogs neither

*Corresponding Author: Liga Kovalcuka. Latvia University of Agriculture, Faculty of Veterinary Medicine, Clinical Institute, 
unilateral nor bilateral application of $1 \%$ tropicamide was shown to cause significant changes of IOP measured after maximal pupil dilation (Hacker and Farver 1988; Molleda et al., 1988; Wallin-Hakanson and Wallin-Hakanson, 2001), although one group of researchers noticed that Siberian Huskies had a greater IOP variability after dilation (Taylor et al., 2007). A study focused on the effects of $0.5 \%$ topical tropicamide in Spanish Water Hounds reported no significant changes in IOP after unilateral application (Molleda et al., 1988) but again, changes in IOP were not measured during dilation.

A previous study in cats showed IOP increases in both eyes $30 \mathrm{~min}$ after unilateral treatment of $0.5 \%$ tropicamide in the right eye. However, $60 \mathrm{~min}$ after treatment the IOP increase of the right eye was significantly greater than the left (Stadtbaumer et al., 2002). In a more recent study by the same author the effects of topical $1 \%$ atropine and $10 \%$ phenylephrine in cats demonstrated a significant IOP increase after atropine, but no effect after phenylephrine. The highest IOP was measured in the treated eye between 5 and 28 $\mathrm{h}$ after treatment and these differences were statistically significant at $1,3,6,12$ and $16 \mathrm{~h}$ post-treatment (Stadtbaumer et al., 2006). In study with normal cats and cats with inherited primary glaucoma, topical $0.5 \%$ tropicamide increased IOP in normal cats those with primary inherited glaucoma (Gomes et al., 2011).

Contradictory findings regarding the effects of atropine on the dynamics of aqueous humour outflow have been reported (Green and Elijah, 1981; Miichi and Nagataki, 1982). Some authors suggested that atropine could change aqueous outflow through cycloplegic actions (Harris, 1968; Valle, 1974); others suggested that mechanical obstruction of iridocorneal angle might be the possible cause of IOP increase (Stadtbaumer et al., 2006). However, these researchers observed that the maximum dilation of the pupil lasted longer than the statistically significant increase of the IOP in cats, arguing against mechanical obstruction of iridocorneal angle (Stadtbaumer et al., 2006).

Few data exist in literature concerning the effects of phenylephrine on the IOP in animals. In monkeys there were no significant changes in the IOP two hours after a single unilateral application of 5\% phenylephrine, but in the same study in human patients IOP was found to have increased significantly (Takayama et al., 2004). In another study with human subjects, $10 \%$ phenylephrine did not cause significant increase in IOP after treatment (Marchini et al., 2003).

Regarding the effects of tropicamide on horizontal pupil diameter (HPD) in dogs, the small amount of data in the literature shows significant HPD increase after topical $0.5 \%$ tropicamide application in both eyes (Wallin-Hakanson and Wallin-Hakanson, 2001). Maximal pupil dilation in cats was observed $2 \mathrm{~h}$ after topical $0.5 \%$ tropicamide (Stadtbaumer et al., 2002). Tropicamide causes significant mydriasis in dogs with and without Therapeutic soft contact lenses (Hatzav et al., 2016). With regard to atropine, maximal pupil dilation was obtained 30-60 min after topical application in dogs, cats and cattle (Gelatt et al., 1973, 1995; Gelatt and MacKey, 1998). In one feline study, HPD started to decrease 24 hours after the topical atropine was administered and after 96 hours the pupil returned to pre-treatment size (Stadtbaumer et al., 2006).

There are contradictory findings in the literature about the effect of phenylephrine on HPD. In cats there is a poor mydriatic effect after application of $10 \%$ phenylephrine (Stadtbaumer et al., 2006). In Rhesus monkeys the maximal pupil dilation occurred 15 minutes after application of two doses of $10 \%$ phenylephrine, although the pupils remained dilated more than 65 minutes (Marchini et al., 2003; Ostin and Glasser, 2004). Rubin and Wolfes (1962), tested phenylephrine in dogs and found maximal dilation at approximately 2 hours.

In the most studies researchers have looked at the IOP at the time of maximal pupil dilation, therefore, our goal in this study was to determine the IOP in the eye immediately after administration of topical mydriatics and in five minutes intervals during the first hour after treatment. The purpose of this study was to determine the effects of topical mydriatics $-0.5 \%$ tropicamide, $1 \%$ atropine sulphate, and $10 \%$ phenylephrine on the IOP and the HPD in the canine eye during the first hour after treatment.

\section{Materials and Methods}

\section{Data}

All animals examined were outpatients at Clinical Institute of the Faculty of Veterinary Medicine at the Latvia University of Agriculture and at the Queen's Veterinary School Hospital, University of Cambridge. This study was approved by the Committee for Animal Protection and Ethical use of Latvian State Food and Veterinary Service and by the Ethics Committee of the Department of Veterinary Medicine, University of Cambridge. In all cases informed consent was obtained from the pet owners for the study.

All animals included in this study were examined by the same person clinically and ophthalmologically, to ensure they were both systemically and ophthalmologically healthy. The clinical examination included signalment (animal breed, age and sex were recorded), general appearance, vital signs (body weight, temperature, heart/pulse rate, respiratory rate), physical examination (systems approach). The ocular examination included direct and indirect ophthalmoscopy (Keeler Practitioner, Windsor, UK), monocular ophthalmoscopy with the Pan Optic ophthalmoscope (Welch Alynn, Romford, UK) and slit 
lamp biomicroscopy (Kowa SL15, Nagoya, Aichi, Japan). Tonometry with the Tonovet tonometer (TonoVet®, Tiolat Ltd. Finland) was a part of the initial examination. Four groups, each containing 10 healthy, randomly assigned dogs of different sexes and breeds were used.

The first group all animals received one drop of $0.5 \%$ tropicamide (Alcon - Couvreur, Belgium) in the right eye, in the second group one drop of $1 \%$ atropine sulphate (Martindale Pharmaceuticals Ltd. UK) in the right eye. In the third group one drop of $10 \%$ phenylephrine hydrochloride was used in the right eye. In the fourth control group, one drop of normal saline was used in the right. The effects of mydriatics on the IOP and the HPD were determined in all groups.

In all treatment groups the first IOP and HPD measurement was taken before treatment $\left(\mathrm{T}_{0}\right)$. After treatment, IOP and HPD were recorded every five minutes in both eyes $\left(\mathrm{T}_{5} ; \mathrm{T}_{10} ; \ldots \mathrm{T}_{60 / 65}\right)$. During all measurements, the animals were handled gently to avoid any tension on the animal's neck which might influence IOP neck (Pauli et al., 2006).

All tonometric measurements were performed by the same person employing rebound tonometry with the Tonovet tonometer (TonoVet®, Tiolat Ltd. Finland), using values that were less than a 5\% standard deviation among six measurements. Use of topical anaesthesia is not required for this tonometer. Horizontal pupil diameter was measured with Jameson calipers under fixed light conditions every five minutes as described above. All measurements were done at approximately same time of day (9.00-11.00 am) because of the effects of light conditions at different times of day on the IOP and the HPD (Gelatt et al., 1981; Giannetto et al., 2009).

\section{Statistical method}

To determine the effect of topical tropicamide, atropine and phenylephrine, the arithmetic mean values (X) and standard deviation (SD) of the IOP and the HPD were calculated for each eye separately. Changes in the IOP and the HPD between eyes and over time period were evaluated using a paired two-sample repeated measures T-test. $\mathrm{P}$ values less than 0.05 were considered to be statistically significant.

\section{Results}

No signs of ocular irritation or pain were detected in animals during the study.

\section{Group 1 (tropicamide)}

Initial pre-treatment IOP are shown in Table 1. Mean IOP values before topical tropicamide application between right and left eye were not significantly different $(\mathrm{P}=0.27)$. The IOP increased from the first post-treatment measurement in the treated eye and at T35 time point IOP had increased from the pretreatment value of mean $8.8 \pm 4.0 \mathrm{mmHg}$ in reaching a maximum 21.6 $\pm 4.1 \mathrm{mmHg}(\mathrm{P}=0.002)$ (Fig. 1.). From this time forward IOP continually decreased until at 60 minutes after treatment the IOP had returned to a T0 values $(\mathrm{P}>0.05)$.

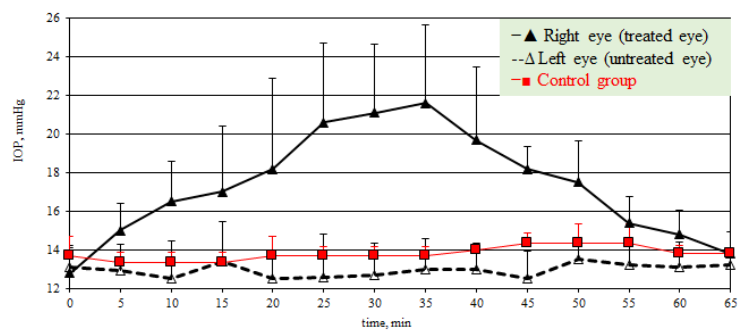

Fig. 1. Effect of unilateral application of $0.5 \%$ tropicamide on the intraocular pressure (mean values) in dogs.

The IOP in the contralateral eye did not significantly increase throughout the treatment period: the IOP values were between $12.5 \pm 1.4 \mathrm{mmHg}$ and $13.5 \pm 1.1$ $\mathrm{mmHg}$ (Table 1). The increase in IOP in the treated eye compared to the untreated eye was statistically significant $(\mathrm{P}=0.002)$ from the $\mathrm{T} 5$ of the measurement period.

Our results concerning the effects of tropicamide on the HPD are shown in Table 2. Before treatment there were no significant differences in the HPD between the eyes. HPD at T5 was increasing relatively to T0 and continued to increase, gaining a maximum mean value of $13.2 \pm 1.7 \mathrm{~mm}$ at T55. During the last five minutes the HPD decreased but still was significantly higher than pre-treatment values $(\mathrm{P}<0.05)$. The increase in pupil diameter from the T0 value until the end of the study was $6.6 \pm 1.2 \mathrm{~mm}$ (Fig. 2).

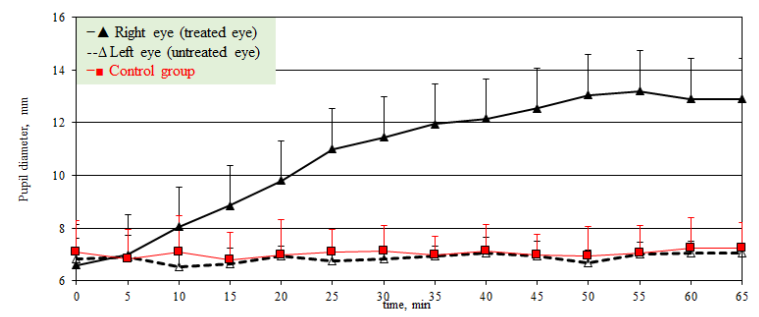

Fig. 2. Effect of $0.5 \%$ tropicamide on the horizontal pupil diameter (mean values) in dogs.

Differences in the HPD between the treated and untreated eye and control group were statistically significant $(\mathrm{P}<0.003)$.

\section{Group 2 (atropine sulphate)}

In the second group, there were no significant differences in IOP between the left and right eyes before application of $1 \%$ atropine sulphate $(\mathrm{P}>0.05)$ (Table 1).

The dynamics of IOP after topical application of $1 \%$ atropine sulphate are shown in Figure 3. 
Table 1. Effect of mydriatics on intraocular pressure (mean values \pm SD) in the dog's right and left eye.

\begin{tabular}{|c|c|c|c|c|c|c|}
\hline \multirow{2}{*}{$\begin{array}{l}\text { Topical } \\
\text { mydriatics }\end{array}$} & \multicolumn{3}{|c|}{ Right eye (treated eye) } & \multicolumn{3}{|c|}{ Left eye (untreated eye) } \\
\hline & $\begin{array}{c}\text { Initial IOP } \\
(\text { mean } \pm \text { SD })\end{array}$ & $\begin{array}{c}\text { Maximal IOP } \\
(\text { mean } \pm \text { SD }), \text { time }\end{array}$ & $\begin{array}{l}\% \text { of IOP } \\
\text { increase }\end{array}$ & $\begin{array}{c}\text { Initial IOP } \\
(\text { mean } \pm \text { SD })\end{array}$ & $\begin{array}{c}\text { Maximal IOP } \\
(\text { mean } \pm \text { SD }), \text { time }\end{array}$ & $\begin{array}{l}\% \text { of IOP } \\
\text { increase }\end{array}$ \\
\hline Tropicamide & $12.8 \pm 1.4$ & $\begin{array}{c}21.6 \pm 4.1 \\
(35 \mathrm{~min})\end{array}$ & $68.8 \% * *$ & $13.1 \pm 1.1$ & $\begin{array}{c}13.5 \pm 1.1 \\
(50 \mathrm{~min})\end{array}$ & $3.1 \%$ \\
\hline Atropine sulphate & $17.7 \pm 3.1$ & $\begin{array}{l}20.3 \pm 3.1 \\
(20 \mathrm{~min})\end{array}$ & $14.7 \% * *$ & $17.3 \pm 2.8$ & $\begin{array}{c}18.1 \pm 3.9 \\
(15 \mathrm{~min})\end{array}$ & $4.6 \%$ \\
\hline $\begin{array}{l}\text { Phelylephrine } \\
\text { hydrochloride }\end{array}$ & $15.0 \pm 3.3$ & $\begin{array}{l}17.3 \pm 4.1 \\
(10 \mathrm{~min})\end{array}$ & $15.3 \%$ & $14.0 \pm 2.8$ & $\begin{array}{l}16.3 \pm 2.3 \\
(20 \mathrm{~min})\end{array}$ & $16.4 \%$ \\
\hline Saline & $16.6 \pm 2.0$ & $\begin{array}{l}17.3 \pm 2.6 \\
(15 \mathrm{~min})\end{array}$ & $4.2 \%$ & $16.6 \pm 2.0$ & $\begin{array}{l}17.3 \pm 2.6 \\
(15 \mathrm{~min})\end{array}$ & $4.2 \%$ \\
\hline
\end{tabular}

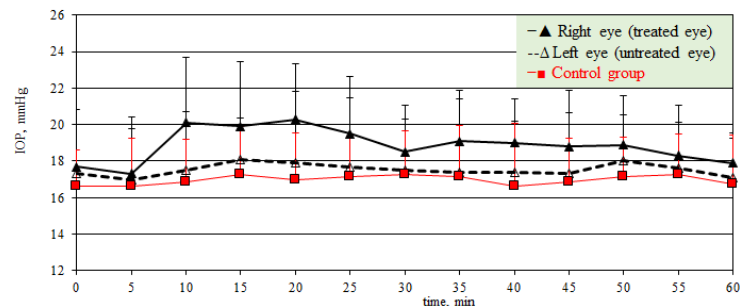

Fig. 3. Effect of unilateral application of $1 \%$ atropine sulphate on the intraocular pressure (mean values) in dogs.

An increase in IOP was seen at T10 after treatment and continued until maximum of IOP at T20 when increase was $2.6 \pm 2.8 \mathrm{mmHg}$ higher than at pre-treatment $(\mathrm{P}=0.008)$. The IOP started to decrease at T25 and continued to decrease until 60 minutes after treatment. The IOP did not significantly change during the last 25 minutes.

At the last measurement the IOP was higher than in the contralateral eye, but this difference was not statistically significant. Mean IOP in the treated eye compared to the untreated eye and the control group values were higher throughout the measurement period but only significantly $(\mathrm{P}<0.05)$ from 10 until 25 minutes after treatment (Fig. 3). In the contralateral eye, the IOP did not significantly increase throughout the treatment period, with IOP values varying from $17.0 \pm 3.2 \mathrm{mmHg}$ to $18.1 \pm 3.9 \mathrm{mmHg}$.

Our results regarding the influence of topical $1 \%$ atropine on the horizontal pupil diameter show that there is no significant differences in the HPD between the eyes $(\mathrm{P}=0.17)$ before topical atropine (Table 2$)$.

The pupil was dilated at T10 after application of $1 \%$ atropine and continued to increase, gaining a maximum mean value of $12.1 \pm 1.7 \mathrm{~mm}$ at 60 minutes $(\mathrm{P}<0.003)$. HPD did not change in two last measurements (Fig. 4). The increase in pupil diameter from the pre-treatment value until the end of the study was $4.2 \pm 2.7 \mathrm{~mm}$. Differences in the HPD between the treated and untreated eye were statistically significant $(\mathrm{P}<0.003)$ from 10 minutes after application of atropine until 60 minutes or the end of study period.

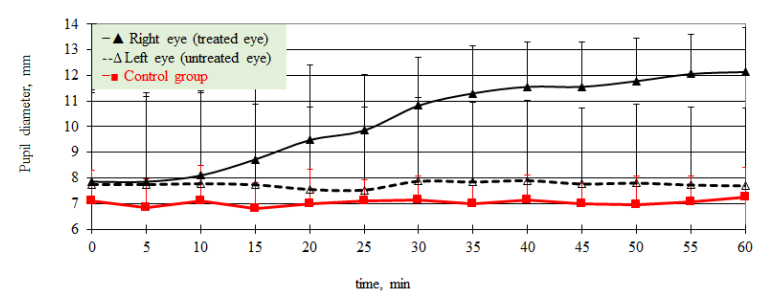

Fig. 4. Effect of $1 \%$ atropine sulphate on the horizontal pupil diameter (mean values) in dogs.

\section{Group 3 (phenylephrine)}

In the third group of dogs we investigated the effects of topical $10 \%$ phenylephrine on the IOP and the HPD. There were no significant differences in the IOP between the right eye and the left eye (Table 1) before topical application of phenylephrine $(\mathrm{P}>0.05)$.

The effect of topical $10 \%$ phenylephrine is shown in Figure 5.

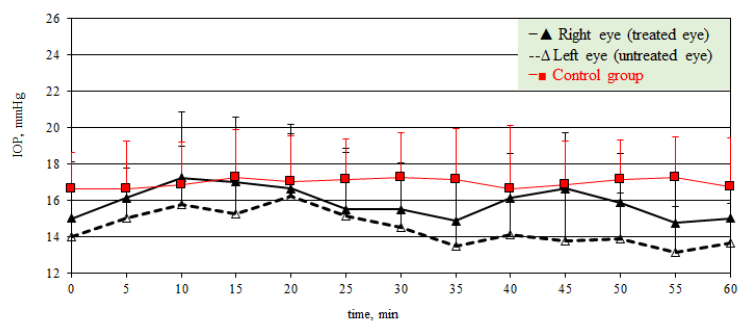

Fig. 5. Effect of unilateral application of $10 \%$ phenylephrine on the intraocular pressure (mean values) in dogs.

In the right eye IOP statistically significantly increased at T5 time point, compared to T0 values. The IOP continued to increase till T10 showing 17.3 \pm 4.1 $\mathrm{mmHg}$, having increase of $2.3 \pm 2.1 \mathrm{mmHg}$ compare to T0 $(\mathrm{P}<0.05)$ and by $\mathrm{T} 35$ the IOP had decreased to $14.9 \pm 2.3 \mathrm{mmHg}$. A second phase of IOP increase was recorded 45 minutes after treatment, with IOP rising to $16.6 \pm 4.1 \mathrm{mmHg}$; however, the second increase of IOP was not statistically significant $(\mathrm{P}>0.05)$. At T55 IOP decreased to $14.8 \pm 1.4 \mathrm{mmHg}$, (Fig. 5), not statistically different from pre-treatment values $(\mathrm{P}>0.05)$. 
Table 2. Effect of mydriatics on horizontal pupil diameter (mean values \pm SD) in the dog's right and left eye.

\begin{tabular}{|c|c|c|c|c|c|c|}
\hline \multirow[b]{2}{*}{ Topical mydriatics } & \multicolumn{3}{|c|}{ Right eye (treated eye) } & \multicolumn{3}{|c|}{ Left eye (untreated eye) } \\
\hline & $\begin{array}{c}\text { Initial HPD } \\
(\text { mean } \pm \text { SD })\end{array}$ & $\begin{array}{c}\text { Maximal HPD } \\
(\text { mean } \pm \text { SD), time }\end{array}$ & $\begin{array}{c}\% \text { of HPD } \\
\text { increase }\end{array}$ & $\begin{array}{c}\text { Initial HPD } \\
(\text { mean } \pm \text { SD })\end{array}$ & $\begin{array}{c}\text { Maximal HPD } \\
(\text { mean } \pm S D), \text { time }\end{array}$ & $\begin{array}{c}\% \text { of HPD } \\
\text { increase }\end{array}$ \\
\hline Tropicamide & $6.6 \pm 0.8$ & $\begin{array}{c}13.2 \pm 1.7 \\
(55 \mathrm{~min})\end{array}$ & $100 \% * *$ & $6.8 \pm 0.9$ & $\begin{array}{l}7.1 \pm 0.6 \\
(40 \mathrm{~min})\end{array}$ & 4.4 \\
\hline Atropine sulphate & $7.9 \pm 3.6$ & $\begin{array}{l}12.1 \pm 1.7 \\
(50 \mathrm{~min})\end{array}$ & $53.2 \% * *$ & $7.7 \pm 3.6$ & $\begin{array}{l}7.9 \pm 3.0 \\
(60 \mathrm{~min})\end{array}$ & $2.6 \%$ \\
\hline $\begin{array}{l}\text { Phenylephrine } \\
\text { hydrochlorid }\end{array}$ & $7.9 \pm 1.5$ & $\begin{array}{l}9.9 \pm 2.0 \\
(60 \min )\end{array}$ & $25.3 \%$ & $7.7 \pm 1.3$ & $\begin{array}{l}6.5 \pm 1.2 \\
(60 \min )\end{array}$ & $-15.6 \%$ \\
\hline Saline & $7.1 \pm 1.2$ & $\begin{array}{l}7.3 \pm 1.2 \\
(60 \mathrm{~min})\end{array}$ & $2.8 \%$ & $7.1 \pm 1.2$ & $\begin{array}{l}7.3 \pm 1.2 \\
(60 \mathrm{~min})\end{array}$ & $2.8 \%$ \\
\hline
\end{tabular}

Importantly, in the left, untreated eye we noticed changes in the IOP (Fig. 5.). As in right eye, the IOP increased in the first five minutes after treatment. Statistically significant IOP increases in the untreated eye were observed 10 and 20 minutes after application of phenylephrine; respectively $15.8 \pm 3.3 \mathrm{mmHg}$ and $16.3 \pm 2.3 \mathrm{mmHg}(\mathrm{P}<0.05)$, an increase of $1.8 \pm 2.1$ $\mathrm{mmHg}$ and $2.3 \pm 2.1 \mathrm{mmHg}$ compared to pre-treatment values. Between 35 and 60 minutes after treatment IOP returned to pre-treatment values $(\mathrm{P}>0.05)$. The mean IOP in the treated eye compared to the untreated eye was significantly higher $(\mathrm{P}<0.05)$ throughout the measurement period, except at 20 and 25 minutes after treatment (Fig. 5). The results regarding the effect of topical $10 \%$ phenylephrine on the HPD are shown in Table 2. The HPD was increased ten minutes after treatment in the right eye (Fig. 6.). Fifteen minutes after treatment it slightly decreased. Statistically significant increases of the HPD were obtained at T20 and T25 minutes after phenylephrine $(\mathrm{P}<0.05)$. At $\mathrm{T} 30$ and $\mathrm{T} 35$ minutes after treatment, the HPD decreased, but it was still significantly higher than the pre-treatment values (Fig. 6). The pupil diameter continued to enlarge 40 60 minutes after treatment, being widest at the time of the last measurement $(9.9 \pm 2.0 \mathrm{~mm})$.

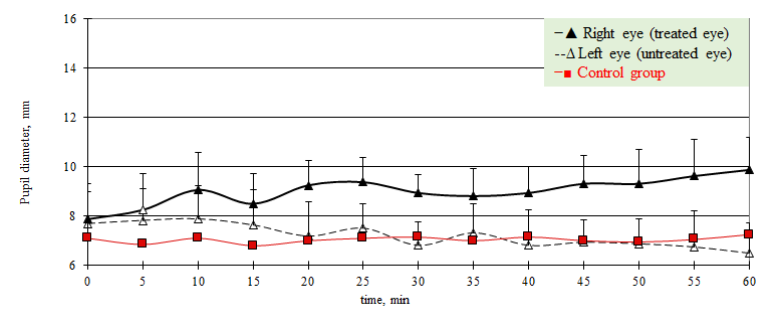

Fig. 6. Effect of $10 \%$ phenylephrine on the horizontal pupil diameter (mean values) in dogs.

In the left eye the HPD slightly decreased 15 minutes after treatment, and by 40 minutes had reached $6.5 \pm 1.2$ mm (Fig. 6), which was statistically significantly lower than before the topical administration of phenylephrine $(\mathrm{P}<0.05)$.

\section{Group 4 (saline)}

In the fourth group of dogs we investigated the effects of topical saline on the IOP and the HPD. There were no significant differences in the IOP between right and left eye $(16.6 \pm 2.0 \mathrm{mmHg})$ before topical application of saline $(\mathrm{P}>0.05)$. The mean IOP of the treated eye compared to the untreated eye did not change significantly throughout the measurement period; the IOP values varied from $16.6 \pm 2.0 \mathrm{mmHg}-17.3 \pm 2.0$ $\mathrm{mmHg}$. Our results regarding influence of topical saline on the HPD show that the mean HPD before application of saline in the right and the left eye was $7.1 \pm 1.2 \mathrm{~mm}$; there were no significant differences in the HPD between eyes. Mean HPD in the treated eye compared to untreated eye did not significantly change throughout the measurement period $(\mathrm{P}>0.05)$.

\section{Discussion}

The IOP before drug administration in all dogs included in this study ranged from $12.8 \pm 1.8 \mathrm{mmHg}$ to $17.7 \pm 3.1$ $\mathrm{mmHg}$. This is similar to previously reported values $16.7 \pm 4.0 \mathrm{mmHg}$ to $18.7 \pm 5.5 \mathrm{mmHg}$ (Miller et al., 1993; Gelatt and Mackay, 1998). In group 1 of this study we investigated the effects of topical $0.5 \%$ tropicamide on the IOP and the HPD during the first hour after treatment, to assess whether there is an increase in the IOP during diagnostic mydriasis. Contrary to the findings of Hacker and Farver (1988) where a significant increase in IOP was not observed after unilateral or bilateral tropicamide application, our research shows a significant increase in IOP immediately after unilateral application of $0.5 \%$ tropicamide while mydriasis was occurring. The IOP in the contralateral eye did not increase, showing no systemic influence. Importantly, the previous studies did not measure IOP throughout the period of mydriasis but merely at the point of maximal mydriasis (Hacker and Farver, 1988; Taylor et al., 2007) while we show an increase during the phase of increasing pupil size, returning to normal at the point of maximal dilation. In similar research in cats, after unilateral application of tropicamide, the IOP significantly increased in the treated eye 1 and $1.5 \mathrm{~h}$ after treatment (Stadtbaumer et 
al., 2006). Our findings showed that during the period of mydriasis in dogs, a statistically significant increase was occurred. In group 2 we determined the effects of the longer-acting parasympatholytic cholinergic blocking agent $1 \%$ atropine sulphate. In the treated eye the IOP increased significantly 10 minutes after application of topical atropine, retaining the maximal effect for 20 minutes. During the same period the IOP in the untreated eye did not change, suggesting that there are no systemic effects of $1 \%$ atropine sulphate after topical application in one eye.

Topical atropine increased the HPD, reaching a maximal pupil size maximum at 30 to 60 minutes after treatment, but without changing HPD in the contralateral eye. This data is similar to that published by Gelatt, demonstrating maximal pupil dilation in dogs, cats and cows at 30-60 min after administration of atropine (Gelatt et al., 1973, 1995).

Latest research shows that $0.5 \%$ tropicamide and $1 \%$ atropine counteracted $0.005 \%$ latanoprost miotic effect, with atropine caused significantly larger mydriasis, but in this combination neither drug counteracted the hypotensive effect of latanoprost during this study period in healthy Labrador retrievers (Kahane et al., 2016). Novel results were obtained with unilateral application of $10 \%$ phenylephrine. As well as increasing IOP in the treated eye, the contralateral eye also showed a significant increase in IOP, demonstrating that phenylephrine is absorbed into the circulation from the eye and has a profound systemic influence. This correlates with research by Pascoe et al. (1994) and Herring et al. (2004), where topical application of phenylephrine increase blood pressure and heart rate, indicating systemic absorption.

Studies regarding the influence of $10 \%$ phenylephrine on canine IOP have not been published in the literature until now, although studies in cats, monkeys and humans demonstrated no significant increase of IOP after topical application of phenylephrine in those species (Marchini et al., 2003; Takayama et al., 2004; Stadtbaumer et al., 2006). Ten percent phenylephrine showed opposite effects on the HPD in the treated as compared to the un-treated eye: in treated eye HPD increased, but in the contralateral eye HPD decreased. These results are perplexing and show the need for further research on this drug.

In group 4, the control group, we investigated the effects of topical saline on the IOP and the HPD during the first hour after treatment. As we anticipated there were no changes in the IOP and the HPD in either eye during the full period of measurement.

\section{Conclusion}

In this study, contrary to previously published reports, we obtained an increase in the IOP in ophthalmically normal canine eyes undergoing mydriasis. The short period during which the IOP rises should not give rise for concern for normal dog eyes, but where glaucoma is possible, as in dogs predisposed by breed to glaucoma, where the iridocorneal angle is already abnormal as shown by gonioscopy or where the contralateral eye already has glaucoma, caution should be taken in the mydriasis of the remaining sighted eye. We do not know whether mydriasis of eyes at risk of glaucoma might lead to a catastrophic permanent increase in IOP. However, we feel that the novel results here should be taken into consideration when performing ophthalmic examinations of dogs with breed or family history of glaucoma, or ones where gonioscopy has shown dysplastic changes in the iridocorneal angle. Further research is needed to define more completely the mechanism or mechanisms that can cause an increase of the IOP.

\section{Conflict of interest}

Authors declare that there was no conflict of interest.

\section{Acknowledgments}

The authors would like to thank assoc. prof. Ilze Matīse - VanHautan from Latvia University of Agriculture Faculty of Veterinary Medicine for her assistance and reviewing the manuscript.

\section{References}

Gartner, S. and Billet, E. 1957. Mydriatic glaucoma. Am. J. Ophthalmol. 43, 975-976.

Gelatt, K.N., Boggess, T.S. and Cure, T.H. 1973. Evaluation of mydriatics in the cat. J. Am. Anim. Hosp. Assoc. 9, 283-287.

Gelatt, K.N., Gum, G.G., Barrie, K.P. and Williams, L.W. 1981. Diurnal variations in intraocular pressure in normotensive and glaucomatous Beagles. Glaucoma 3, 121-124.

Gelatt, K.N., Gum, G.G. and Mackay, E.O. 1995. Evaluation of mydriatics in cattle. Vet. Comp. Ophthalmol. 5, 46-49.

Gelatt, K.N. and Mackay, E.O. 1998. Distribution of intraocular pressure in dogs. Vet. Ophthalmol. 1, 109-114.

Giannetto, C., Piccione, G. and Giudice, E. 2009. Daytime profile of the intraocular pressure and tear production in normal dog. Vet. Ophthalmol. 12(5), 302-305.

Gomes, F.E., Bentley, E., Lin, T.L. and McLellan, G.J. 2011. Effects of unilateral topical administration of $0.5 \%$ tropicamide on anterior segment morphology and intraocular pressure in normal cats and cats with primary congenital glaucoma. Vet. Ophthalmol. 14(Suppl. 1), 75-83.

Green, K. and Elijah, D. 1981. Drug effects on aqueous humor formation and pseudofacility in normal rabbit eyes. Exp. Eye Res. 33, 239-245.

Grozdanic, S.D., Kecova, H., Harper, M.M., Nilawera, W.M., Kuehn, M.H. and Kardon, R.H. 2010. Functional and structural changes in the canine 
model of hereditary primary angle-closure glaucoma. Invest. Ophthalmol. Vis. Sci. 51, 255263.

Hacker, D.V. and Farver, T.B. 1988. Effects of tropicamide on intraocular pressure in normal dogs. J. Am. Anim. Hosp. Assoc. 24, 411-415.

Harris, L.S. 1968. Cycloplegia- induced intraocular pressure elevations a study of normal and openangle glaucomatous eyes. Arch. Ophthalmol. 79(3), 242-246.

Harris, L.S. and Galin, M.A. 1969. Cycloplegic provocative testing. Arch. Ophthalmol. 81, 356358.

Hatzav, M., Bdolah-Abram, T. and Ofri, R. 2016. Interaction with therapeutic soft contact lenses affects the intraocular efficacy of tropicamide and latanoprost in dogs. J. Vet. Pharmacol. Ther. 39(2), 138-143.

Herring, I.P., Jacobson, J.D. and Pickett, J.P. 2004. Cardiovascular effects of topical ophthalmic $10 \%$ phenylephrine in dogs. Vet. Ophthalmol. 7, 41-46.

Kahane, N., Raskansky, H., Bdolah-Abram, T. and Ofri, R. 2016. The effects of topical parasympatholytic drugs on pupil diameter and intraocular pressure in healthy dogs treated with 0.005\% latanoprost. Vet. Ophthalmol. 19, 464-472.

Marchini, G., Babighian, S., Tosi, R., Perfetti, S. and Bonomi, L. 2003. Comparative study of the effects of $2 \%$ ibopamine, $10 \%$ phenylephrine, and $1 \%$ tropicamide on the anterior segment. Invest. Ophthalmol. Vis. Sci. 44, 281-289.

Miichi, H. and Nagataki, S. 1982. Effects of cholinergic drugs and adrenergic drugs on aqueous humor formation in the rabbit eye. Japanese J. Ophthalmol. 26, 425-436.

Miller, P.E., Pickett, J.P., Majors, L.J. and Kurzman, I.D. 1993. Clinical comparison of the Mackay-Marg and Tonopen applanation tonometers in the dog. Pro. Vet. Comp. Ophthalmol. 3, 67-73.

Molleda, J.M., Frau, M., Lopez, R., Bandrés, P. and Novales, M. 1988. Acción de los midriáticos sobre la presión intraocular en el perro. Med. Vet. 5, 2932.

Ostin, L.A. and Glasser, A. 2004. The effects of phenylephrine on pupil diameter and accommodation in Rhesus monkeys. Invest. Ophthalmol. Vis. Sci. 45, 215-221.

Pascoe, P.J., Ilkiw, J.E., Stiles, J. and Smith, E.M. 1994. Arterial hypertension associated with topical ocular use of phenylephrine in dogs. J. Am. Vet. Med. Assoc. 205(11), 1562-1564.

Pauli, A.M., Bentley, E., Diehl, K.A. and Miller, P.E. 2006. Effects of the application of neck pressure by a collar or harness on intraocular pressure in dogs. J. Am. Anim. Hosp. Assoc. 42, 207-211.
Rengstorff, R.H. and Doughty, C.B. 1982. Mydriatic and cycloplegic drugs: a review of ocular and systemic complications. Am. J. Optom. Physiol. Opt. 59, 162-177.

Ribeiro, A.P., Crivelaro, R.M., Teixeira, P.P., Trujillo, D.Y., Guimarães, P.J., Vicente, W.R., Martins Bda, C. and Laus, J.L. 2014. Effects of different mydriatics on intraocular pressure, pupil diameter, and ruminal and intestinal motility in healthy sheep. Vet. Ophthalmol. 17(6), 397-402.

Rubin, L.F. and Wolfes, R.L. 1962. Mydriatics for veterinary ophthalmoscopy. J. Am. Vet. Med. Assoc. 140, 137-141.

Shaw, B.R. and Lewis, R.A. 1986. Intraocular pressure elevation after pupillary dilation in open-angle glaucoma. Arch. Ophthalmol. 104, 1185-1188.

Smith, C.M. and Reynard, A.M. 1992. Antimuscarinic Drugs. In Textbook of Pharmacology, Eds., Melsaac, R.J.: W.B. Saunders Company Philadelphia, pp: 108-115.

Stadtbaumer, K., Frommlet, F. and Nell, B. 2006. Effects of mydriatics on intraocular pressure and pupil size in the normal feline eye. Vet. Ophthalmol. 9, 233-237.

Stadtbaumer, K., Kostlin, R.G. and Zahn, K.J. 2002. Effects of topical $0.5 \%$ tropicamide on intraocular pressure in normal cats. Vet. Ophthalmol. 5, 107112.

Takayama, J., Mishima, A. and Ishii, K. 2004. Effects of topical phenylephrine on blood flow in the posterior segment of monkey and aged human eyes. Japanese J. Ophthalmol. 3, 243-248.

Taylor, N.R., Zele, A.J., Vingrys, A.J. and Stanley, R.G. 2007. Variation in intraocular pressure following application of tropicamide in three different dog breeds. Vet. Ophthalmol. 10(Suppl. 1), 8-11.

Valle, O. 1974. Effect of cyclopentolate on the aqueous dynamics in incipient or suspected open-angle glaucoma. Acta Ophthalmol. Suppl. 123, 52-60.

Wallin-Hakanson, N. and Wallin-Hakanson, B. 2001. The effects of topical tropicamide and systemic medetomidine, followed by atipamezole reversal, on pupil size and intraocular pressure in normal dogs. Vet. Ophthalmol. 4, 3-6.

Ward, D.A. 1998. Clinical ophthalmic pharmacology and therapeutics. In Veterinary Ophthalmology, Eds., Gelatt, K.N., $\quad 3^{\text {rd }}$ ed. Lippincott/Williams\&Wilkins, Philadelphia, pp: 291-354.

Wu, S.C., Lee, Y.S., Wu, W.C. and Chang, S.H. 2015. Acute angle-closure glaucoma in retinopathy of prematurity following pupil dilation. BMC Ophthalmol. 15, 96. doi: 10.1186/s12886-0150099-7. 